\title{
Editors' Introduction
}

\section{Sandra L. Tarabochia}

Norman OK

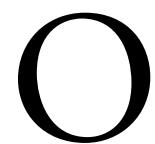

ur collective vision for Writers: Craft \& Context began to germinate 1.5 years ago when the three of us looked around at the state of academic publishing. Like many, we were frustrated with the lack of equitable representation on editorial teams, editorial boards, among published authors, and in accepted expressions of scholarly writing. We saw an opportunity for those of us who write, teach writing, and study writers to draw more fully on the dynamic types of composing we do to more fully represent, support, and value the lived experience of writers. We craved a collaborative, generative space for scholars of all stripes-from across disciplines, from within and beyond the academy - to share and learn from poetry, interviews, letters, creative nonfiction, pedagogical reflection, parable, architecture, and more.

Pursuing our vision for such a space was necessary and urgent, we realized, because although the field of writing studies boasts a long history of resisting standardization, those values do not always play out in published scholarship. The three of us were aware of meaningful work, including our own, that would never "fit" in the current landscape of scholarly publishing because it refuses to be standardized. That reality was troubling on many levels. Of course the field is missing out by failing to be shaped by those voices and projects; scholarly conversations remain untouched by insights that matter now more than ever; scores of readers are resigned to the fact that they will never read their stories, see their realities in the field's published literature. What's more, these "misfit" writers are forced to suffer a traumatizing, inhumane cycle of submission and rejection, compelled to try again and again to fit their feet into misshapen shoes crafted by a meritocratic system that was never designed to work for them.

In light of the budding movement toward inclusive publishing, we realized nothing short of transformation would address the interconnected problems we observed in our field. We began to imagine a journal that would disrupt the system on multiple fronts, that would actively confront the standardization of writing - in form and process - that would resist the burgeoning neoliberal agenda that seems to justify, perpetuate, and sustain the very forces we felt compelled to resist. In an effort to push against forms of oppression through standardization, we frame our ideological goals for this journal with critical lenses that challenge dominant ideologies and liberal claims of neutrality, equal opportunity, objectivity, color blindness, and merit in the craft and publication of writing (Dixson \& Rousseau, 2006, p. 4; Solórzano \& Delgado Bernal, 2001, p. 313). In response to a lack of inclusivity, justice, and access to publishing, we challenge dominant ideologies perpetuated through standardization of content and process. Doing so is difficult because of resistance from those who invoke abstract liberal concepts like equal opportunity-a concept not easily examined when the ideology supporting this concept finds its foundation in hegemonic beliefs and practices of meritocracy. However, too many established journals claim neutrality in their selection of

\section{Michele Eodice}

Lawrence KS

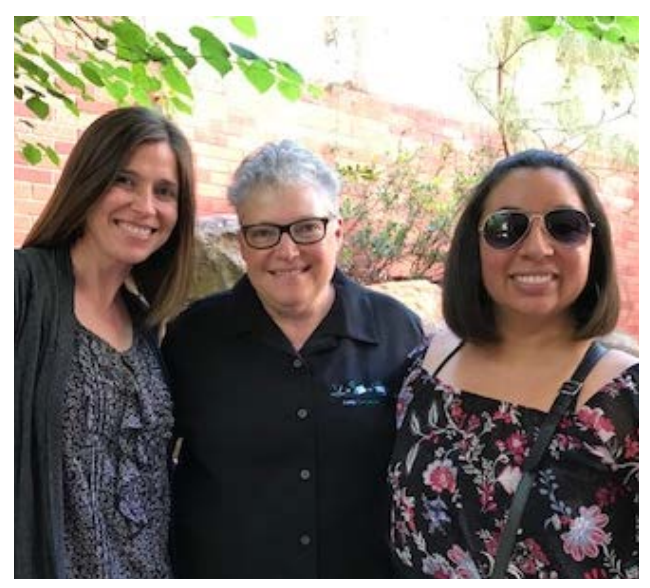

Our Open Journal System (OJS) platform is maintained at the University of Oklahoma. We'd like to acknowledge that site as supportive, but also troubling. Oklahoma is home to 39 tribal nations, each of which has a distinctive culture, history, and government. We acknowledge that the history of the university and the state represents settler colonialism and remains in tension with what we now understand about the lands proclaimed "unassigned" and opened for white settlement in 1889. 
scholarship and justify the rejection of genre-pushing projects on the "colorblind" basis of merit and "fit." Each of us has witnessed and experienced the effects of dominant ideologies on and as writers. From our collective lived experiences, we know how real people are affected by hostility and hate every day. As our personal origin stories are an important driver of our collective vision for the journal, we share them now.

\section{SANDY'S STORY}

I came to this project as a writer who has had trouble finding the right venue for my research on the lived experiences of faculty writers. I found myself making the argument again and again that writing studies should pay attention to this particular group of writers and doing backflips to convince reviewers for mainstream journals that their readers had a stake in what I had to offer. How could my findings possibly matter to readers who worked with undergraduate or graduate writers, but not faculty? Of course the fact that reviewers and readers did not see themselves as faculty writers with something to gain from my research, nor acknowledge the role they play in the lives of faculty writers as mentors, chairs, peer evaluators, tenure-committee members, reviewers, editors, etc., was part of the point I was trying to make about how we ignore the development of faculty writers to our detriment.

I've had trouble convincing my institution to fund my research as well. I've collected the following feedback from grant award committees: "The PI does not address this project as an intervention which could have more impact in the context of research." "The plan has very little scientific rigor ... a approach is not randomized ... project is backward looking with no real predictive powers . . . unclear that the results can be generalizable to a larger scholarly community ... seems to be little impact potential on this field or any other." These responses are disheartening, especially as I repeatedly hear from faculty in my study, particularly women and faculty from minoritized and underrepresented groups, how institutional structures, such as internal grant criteria and procedures, tenure and promotion processes, and scholarly review and publication practices are soul-sucking, cruel, disheartening, and traumatizing. The disconnect between writers' experiences and the institution's and field's interest in understanding and supporting them is striking. It has fueled my conviction that writers need a place (many places) to read and publish about writers and the work of writing.

\section{AJA'S STORY}

My experiences with publishing and journals are not (to this point) in editing but as an author who has had to shop around my work in critical race counterstory to several different journals. As nothing is beyond critique, my work in counterstory has experienced its share of skeptics, detractors, and naysayers. As Catherine Prendergast
(2003) has observed, counterstorytellers "have often been noted (and often faulted) not so much for their arguments-what they are saying — as for their departures from standard ... discourse- how they are saying" (p. 46). In my experience, reviewers for mainstream journals in rhetoric and writing studies express an interest in genre-pushing work yet still insist this work must be amenable to mainstream writing standards.

Exemplary counterstory writer and teller Derrick Bell (1995) has said these critics "are not reluctant to tell us what [the writing] ought to be. They question the accuracy of the stories, fail to see their relevance, and want more of an analytical dimension to the work-all this while claiming that their critiques will give this writing a much-needed "legitimacy' in the academic world" (p. 907). Critical race theorists Richard Delgado and Jean Stefancic (2017) advise that this kind of response should come as no surprise, as the critiques of counterstory demonstrate that this sort of feedback is nothing original, field specific, or new. Paradigms resist change, and methods and genres that seek to challenge and change reigning paradigms historically spark stubborn resistance (p. 102). I believe Writers: Craft and Context is a fitting endeavor to join in with my fellow editors and authors as we embark on crafting meaningful genre- and boundary-shattering work.

\section{MICHELE'S STORY}

WCC caps my experience editing two journals. But the aims and scope of those journals (Kansas English and The Writing Center Journal) are set by larger institutional bodies. We envisioned a journal of our own invention that could provide a new space for fresh aims and scope defined by the writers themselves. We wanted to invite new knowers who resist privileging only argument and evidence bound up in traditional forms and genres. We wanted to show, not tell, how we value lived experience, epistemic diversity, and the ways art can help us understand writers and writing. As someone who is "phasing out" of professional life, I can think of no more satisfying and creative way for me to do some of my favorite things - work with writers, learn with these editors, and write my own poetry again.

Thus, our vision for Writers: Craft and Context aims for a "narrative plentitude" in the ways Viet Thanh Nguyen (2018) describes, with a goal of radical inclusivity that aspires for diverse crafts and contexts to expand representation in this journal. We, the managing editors, along with our large collaborative editorial team, recognize that the journal's "vibrancy, relevance, and, most crucially, ethical core depend on a consistent, rigorous, and measurable commitment to addressing [scholarly publication's] exclusionary history with regard to people of color, women, LGBTQ+ individuals, people with disabilities, non-citizens, and those who stand at the intersections of these identities and more" (Calafell, 2019). Therefore, WCC is a site for "inclusion activism" that seeks to "challenge operations 
that exclude and diminish the experience and knowledge of some while propping up that of others, and to be supportive of those who have not traditionally had access to or representation within field conversations" (Blewett, LaVecchia, Micciche, \& Morris, 2017, pp. 274-275). For us, that means holding ourselves, authors, reviewers, and board members accountable to the writers and communities with, about, and for whom we publish (Gumbs, 2019; Pritchard, 2019). In a departure from traditional academic journals, we promise to be a venue for writers "to speak with (rather than for and over) others' communities" (Black, Latinx, American Indian et al., 2018). We've made inclusive citation practices part of our review criteria in ways that resist the all-too-common "rhetorical tokenism that leads to a lack of recognition of the fullness of people's contributions" (Pritchard, 2019). Through these commitments, we seek to "enlarge and help to grow our scholarly communities rather than follow well-worn grooves" (Blewett et al., 2017, p. 275).

Toward that end, Writers: Craft \& Context seeks to publish a wide array of material focused on writers: the work they do, the contexts in which they compose and circulate their work, how they are impacted by policies and pedagogies (broadly conceived), and how they develop across the lifespan. Given our goals for the journal, including equitable representation of writers, experiences, expertise, and perspectives, it is important to us that our wide target audience have access to our content. We see open access as a vital part of democratizing knowledge construction and knowledge sharing. We are invested in publishing contributions from a range of academic fields such as writing studies, cultural studies, education, psychology, sociology, literature, and modern languages, as well as from community experts outside academia, including program leaders, activists, volunteers, artists, and others who see, support, and do the work of writing in nonacademic contexts. As you will note from the contents of our inaugural issue, we publish traditional and creative genres including research articles, reflections on methodology, pedagogy pieces, collaborative or multivoice works, collages, essays, creative nonfiction, interviews, and more. Our flexibility with genre allows for new ways of thinking, composing, and meaning making as we invite authors to pursue shared goals through innovative methods.

\section{Inaugural Issue}

This particular issue beautifully represents the sheer range of genres our journal supports and is invested in publishing. Too many have had negative experiences with publishing, experiences that evidence epistemic exclusion (Buchanan, Dotson, O'Rourke, Rinkus, Settles, \& Vasko, 2017) in which genre-pushing pieces that reflect authentic intellectual engagement between knowers and how they know are often rejected. In addition to a range of genres, this issue highlights a diversity of contributors. We hear from life-long writers who are at various stages along the continuum of publishing experience, spanning from early-career academic writers to long-established writer-scholars. Some of our authors have breathed new life into texts they never thought they'd publish; academics who are also poets and creative writers composing outside standard academic boundaries have found WCC a welcome venue.

In "We Read Your Letter," Yanira Rodríguez, Benesemon Simmons, Vani Kannan, Sherita V. Roundtree, and B. López, a collective of early-career professors and doctoral students, have crafted a letter written to and in praise of teacher-scholar-activist Dr. Carmen Kynard. Through this epistolary engagement, Rodriguez et. al respond to Kynard's "On Graduate Admissions and Whiteness: A Love Letter to Black/Brown/ Queer Graduate Students Out There Everywhere" with modalities that range from poetry, to visual imagery, to sound recordings, to creative approaches in layout and design. The authors collectively engage Kynard's message with their own message of radical feminist love, coalition, and solidarity in refusal of the academy's imperialistic violences that aim to create fissures between and amongst Black/ Brown/Queer/Indigenous graduate students of color. Aside from the important message contained within this letter, this contribution is a brilliantly conceived and executed example of the genre and modality-specific possibilities we invite potential authors to imagine for their own contributions to this journal.

Demonstrating a range of contexts, with particular focus on relationships among people in specific places, poet and writing instructor Silke Feltz offers three poems entitled "Daughter of India," "rockstar, revisited," and "We Left Texas on Cinco de Mayo." In "Daughter of India," Feltz takes her readers 'round the track on a run with sensory detail that evokes a pumping heart and the heat of sensation. "rockstar, revisited" will wash over readers like a smooth and melancholy breeze of nostalgia. This tribute emanates an aching for moments long ago and longed for but no longer part of the present or the future. Rounding out Feltz's contribution is "We Left Texas on Cinco de Mayo," a poem lauded by a reviewer as speaking eloquently "to the pain of moving in life, in relationships, but also the hope for something new on the horizon." Feltz's attentiveness to the sonic dynamics of storytelling makes her poems a welcome genre-option contribution to this issue.

Lida Colón presents an interview with her father, Robert Colón, titled "Telling Stories to Anyone Who Will Listen." Through this interview, interspersed with critical self-reflection and critique, Colón meditates on aspects of writing, revision, and storytelling through an intergenerational lens between the author and her father, Robert. A first-year doctoral student in Syracuse's Composition and Cultural Rhetoric program, Colón's exploration of self within a writing context is informative and illuminating, as her presentation of Robert's story assists readers in identifying connections we too often neglect between the lived practice of writing and scholarship. Robert, an engaging interview subject, walks us through his writing process, growth, exploration, and revision practices as Colón lovingly illustrates the connections between who Robert is as a 
writer and who she is and what she envisions as the connections of writing lives and practices. This exercise in intergenerational engagement through the genre of interview is in concert with the intergenerational gestures made by Rodríguez et. al, but presents yet another genre we encourage potential contributors to endeavor.

In "Still Christmas," Paula Mathieu explores the lasting effects of family silences and how a childhood filled with secrets propelled her to teach writing, to inspire and empower others to voice their stories. An associate professor at Boston College, Mathieu is the author of Tactics of Hope: The Public Turn in English Composition (2005) and two essay collections on place-based writing and community publishing. Resonant with her interest in contemplative practices and pedagogies, Mathieu uses creative nonfiction to mine and share personal stories, stories that have been buried and silenced for some time. She does so with the hope of establishing human connection with others who may also be suffering the high costs of silence, that we may see our stories reflected here and take heart. "Still Christmas" is at once a heart-wrenching story of loss and longing and hopeful meditation on the power of writing to "restory" lives. It is a provocative look at the "lived experience" of one writer and striking commentary about how and why we write.

In "Publishing: A Conversation/Publishing a Conversation," Cayo Gamber, Associate Professor of Writing and Women's, Gender, and Sexuality Studies at George Washington University, offers a poignant depiction of the embodied experience of writing for publication. Gamber is no stranger to that experience, having published widely on representations of the Holocaust and the role of popular culture in creating Western notions of girlhood and womanhood. Through reflections that are often hilarious, sometimes tragic, and always spot on, Gamber's contribution to this issue guides readers on the emotional journey to which publishing writers submit in perpetuity. We feel the imaginative force of anticipation, the consuming spiral of reflection, the irrational certainty of envy, the delicious sustenance of amity, the never-enoughness of perpetual, high-stakes evaluation, and the steadfastness of persisting despite the toll it all takes on bodies, minds, and souls. We can imagine sharing this essay with graduate students new to the publishing game and keeping a copy in our own top drawers to remind us that writers are not alone and to remind us that, as the mission of this journal attests, writing for publication need not be traumatizing or inhumane.

In "On Cucuys in Bird's Feathers: A Counterstory as Parable," Aja Y. Martinez, author of Counterstory: The Rhetoric and Writing of Critical Race Theory, extends her groundbreaking work with counterstory, using the power of the parable to incite reflection and critical conversation about mentorship and writing/publishing. Modeling an expansive approach to genre, voice, style, and citation practice, Martinez, an assistant professor, throws into relief the power imbalances that plague discussions about these issues, inviting readers to see ourselves in the fictional characters and situations depicted in the piece. Web links, according to one reviewer, create a "realistic representation of [the] web of influences we draw from as we synthesize ideas and create relationships; that is, [they] work to challenge the mind and body dichotomy that the Dominant reinforces, embodying the reality of the relationship between thoughts and feelings we experience all the time." Martinez offers lessons for surviance in her parable, in much the same way we have traditionally taught our young through stories told around a fire and down through the generations.

Rounding out our first issue's counterstory-specific contributions is Frankie Condon's counterstory "A Bridge across Our Fears: Excerpts from the Annals of Bean." In this narrative that evokes aspects of feminist critical self-reflection and critical whiteness studies, Condon, an associate professor and author of I Hope I Join the Band, discusses her own subjectivity as a white woman in relation to a composite character, Bean, who exemplifies the trope of privileged white male students in our teaching contexts. Through counterstory, Condon's text contributes to the ongoing conversation on antiracism and reflective pedagogy, and we believe this work will appeal to many teachers who are interested in Neisha-Anne Green's call for accomplices (and introduce Green and her concept to new readers). This work adds to the larger conversation on what Asao Inoue (2015) identifies as "whitely ways," and as one reviewer remarked, "It calls out white women who claim to want change but who are unwilling to 'do' the hard work necessary." Condon makes clear that an antiracist agenda can lead to failure, and because of this (or in spite of this), the process is ongoing and recursive but worth the effort nonetheless.

We hope these two counterstory pieces (Condon and Martinez) are the first of many contributions that engage the methodology and method of counterstory. We intend to hold space in this journal for explicit counterstory contributions in subsequent issues.

\section{***}

At the time of this writing we are all living life within a global pandemic that fuels chaos and anxiety, but also within the \#BlackLivesMatter movement, which is a socio-political moment that instills revolutionary hope. We feel privileged and grateful to be in the position to voluntarily edit a radically inclusive journal in this moment. In the pages of this journal, readers will find pleasure, opportunities to delight in humor, and a "turning to art to organize the chaos" (Boquet \& Eodice, 2019), an experience that brings us closer to each other as we empathize with the narratives of relationality these authors share. Ours is a shared experience.

We are deeply grateful to the collective of individuals and institutional entities who have supported the launch of this journal. Our host, the Office of Open Initiatives \& Scholarly Communication of OU Libraries, has offered wonderful digital hospitality. We are especially grateful to our reviewers, who have voluntarily invested physical, intellectual, and emotional energy in the writing and the writers included here. Reviewers wholeheartedly embraced our 
vision for this journal, which features a review process committed to respecting the labor of authors and reviewers. Reviewers submitted detailed feedback that acknowledged the dignity and humanity of authors and worked in good faith to help authors realize their goals for their writing. Both authors and reviewers have expressed how meaningful it was for them to participate in this process. One author lovingly shared thank-you notes and homemade biscotti that we passed along to reviewers as a token of gratitude, remarking on the novelty of a review process that is both critical and compassionate, rigorous and invigorating.

In closing, we thank readers for spending time with Writers: Craft \& Context and warmly invite writers to submit work that is creative and experimental and that pushes genre into places you didn't think you could go with your writing.

\section{References}

Bell, Derrick A. (1995). David C. Baum Memorial Lecture: Who's Afraid of Critical Race Theory? University of Illinois Law Review, 1995(4), 893-910.Blewett, Kelly, LaVecchia, Christina M., Micciche, Laura R., \& Morris, Janine. (2019). Editing as inclusion activism. College English, 81(4), 273-296.

Boquet, Elizabeth H., \& Eodice, Michele. (2019). Foreword: Turning to art to organize the chaos. In Steven J. Corbett, Jennifer Lin LeMesurier, Teagan E. Decker, \& Betsy Cooper (Eds.), Writing in and about the performing and visual arts: Creating, performing, and teaching (pp. xiiixiv). Across the Disciplines Books. WAC Clearinghouse and University Press of Colorado. Available at http://wac. colostate.edu/books/atd/performing/

Buchanan, Nichole T., Dotson, Kristie, O'Rourke, Michael, Rinkus, Marisa A.. Settles , Isis H., \& Vasko, Stephanie E. (2017). Toolbox Workshop Report: Creating Inclusive Excellence Grant Project-May 4 and 24, 2017. Michigan State University Toolbox Dialogue Initiative. https:// inclusion.msu.edu/_assets/documents/research/ EpistemicExclusionReport.pdf

Calafell, Bernadette Marie, \& undersigned. (2019, June 28). An open letter on diversity in the communication discipline. Retrieved from http://bernadettemariecalafellphd. com/?page_id $=847$

Delgado, Richard, \& Stefancic, Jean. (2017). Critical race theory: An introduction (3rd ed.). New York UP.

Dixson, Adrienne D., \& Rousseau, Celia K. (Eds.). (2006). Critical race theory in education: All God's children got a song. Routledge.

Green, Neisha-Anne. (2018). Moving beyond alright: And the emotional toll of this, my life matters too, in the writing center work. Writing Center Journal, 3(1),15-34. Retrieved from www.jstor.org/stable/26537361
Gumbs, Alexis Pauline. (2019, August 7). Brilliance remastered: About. Brilliance Remastered. Retrieved from https://www. alexispauline.com/brillianceremastered/

Inoue, Asao B. (2015). Antiracist writing assessment ecologies: Teaching and assessing writing for a socially just future. WAC Clearinghouse/Parlor Press.

Martinez, Aja Y. (2020). Counterstory: The rhetoric and writing of critical race theory. Studies in Writing and Rhetoric. NCTE.

Nguyen, Viet Thanh, and Tran, Vu. (2018, Oct. 11). Nguyen, Viet Thanh, and Vu Tran: Narrative plentitude. Retrieved from https://vietnguyen.info/2018/viet-thanh-nguyen-and-vutran-narrative-plentitude-talks-at-google

Black, Latinx, American Indian, Queer, Asian/Asian American Caucuses. (2018). "Open Letter." NCTE \& CCCC, December. https://docs.google.com/document/d/1fsDD5Y-KyQ007ILiMDmulv7QV2TJ07qMUxJqQZIzHk/edit

Prendergast, Catherine. (2003). Literacy and racial justice: The politics of learning after Brown v. Board of Education. Southern Illinois UP.

Pritchard, Eric D. (2019, July 8). "When you know better, do better": Honoring intellectual and emotional labor through diligent accountability practices. [blog post]. Retrieved from http://carmenkynard.org/featured-scholareric-darnell-pritchard-when-you-know-better-do-betterhonoring-intellectual-and-emotional-labor-through-diligentaccountability-practices/

Solórzano, Daniel G., \& Bernal, Dolores Delgado. (2001). Examining transformational resistance through a critical race and Latcrit theory framework: Chicana and Chicano students in an urban context. Urban Education, 36(3), 308-342.

$\begin{array}{ll}\begin{array}{l}\text { Thank you - Reviewers V1 } \\ \text { Steven Alvarez }\end{array} & \begin{array}{l}\text { Thank you - OU Support } \\ \text { Haley Fulco } \\ \text { Sara Huber }\end{array} \\ \text { Zachary C. Beare } & \text { Nick Cousino } \\ \text { Elizabeth H. Boquet } & \text { Jen Waller } \\ \text { OU Writing Center } \\ \text { Timothy Bradford } & \\ \text { Christina Cedillo } & \\ \text { Erica Cirillo-McCarthy } & \\ \text { Frankie Condon } & \\ \text { Todd Craig } & \\ \text { Laura Gonzales } & \\ \text { Dana Kinzy } & \\ \text { Shannon Madden } & \\ \text { Londie Martin } & \\ \text { Cruz Medina } & \\ \text { Jaime Armin Mejía } & \\ \text { Anna K. (Willow) Treviño } & \end{array}$

